\title{
Geographical Distribution of Myasthenia Gravis in Northern Europe - Results from a Population-Based Study from Two Countries
}

\author{
Marion I. Boldingh ${ }^{a} \quad$ Angelina H. Maniaol ${ }^{a} \quad$ Cathrine Brunborg ${ }^{a} b$ \\ Luuk Dekker $^{d}$ Anne T. Heldalc A.F. Lipkad Trine H. Popperud ${ }^{\mathrm{d}}$ Erik H. Niks ${ }^{d}$ \\ J.J.G.M. Verschuuren ${ }^{d}$ Chantal M.E. Tallaksen ${ }^{\mathrm{a}, \mathrm{e}}$ \\ ${ }^{a}$ Department of Neurology, Oslo University Hospital, Ullevål and Rikshospitalet, Oslo, ${ }^{b}$ Oslo Centre for Biostatistics \\ and Epidemiology, Research Support Services, Oslo University Hospital, Ullevål, Oslo, 'Department of Clinical

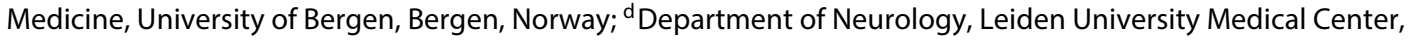 \\ Leiden, The Netherlands; ${ }^{\mathrm{e}}$ Institute of Clinical Medicine, University of Oslo, Oslo, Norway
}

\section{Key Words}

Myasthenia gravis, prevalence - Muscle specific tyrosine kinase antibody - Acetylcholine receptor antibody . Late-onset myasthenia gravis - Phenotype

\begin{abstract}
Objectives: To compare the prevalence of myasthenia gravis (MG) subgroups based on immunological markers and clinical presentation in two geographically complete MG populations in northern Europe. Methods: This cross-sectional study included all living MG patients in Norway and a regional cohort from the Netherlands. Patients were identified using their hospital registration codes. Medical charts of subjects $>16$ years were reviewed. Inclusion criteria were clinical MG, a positive antibody test for acetylcholine receptor (AChR MG) or muscle-specific kinase (MuSK MG), or if seronegative MG, confirmed by an electrophysiological test. Results: 1,205 MG patients (534 Norwegians and 671 Dutch) fulfilled the criteria, giving a higher point prevalence in the Netherlands (167/ million, 95\% Cl 155-180) than in Norway $(138 /$ million, $95 \% \mathrm{Cl}$ 126-150). In particular, rates of AChR MG (143 vs. 111/million), MuSK MG (6.5 vs. 0.5/million), and ocular phenotype (62 vs. $24 /$ million) were higher in the Netherlands. Conclu-
\end{abstract}

(c) 2015 S. Karger AG, Basel

0251-5350/15/0444-0221\$39.50/0 sion: Novel findings are an AChR MG geographical northsouth gradient and a 2.6-fold more ocular MG patients in the Netherlands than in Norway. The MuSK MG latitudinal gradient supports the notion of a north-south gradient in Europe, with a higher prevalence in the south. The variation is probably explained by genetic differences between the populations, in addition to environmental interactions.

(c) 2015 S. Karger AG, Basel

\section{Introduction}

Myasthenia gravis (MG) is an autoimmune neuromuscular disorder with a prevalence of $77-317 /$ million inhabitants in Europe [1-6]. The disease occurs predominantly in adults and the typical clinical symptoms are ocular, bulbar, or generalized weakness and fatiguability. In $85 \%$ of the cases, pathogenic antibodies like acetylcholine receptor antibodies (AChR MG) or muscle-specific kinase antibodies (MuSK MG) are recognized $[7,8]$. In the remaining subset, no antibodies are identified, but patients have a phenotype similar to AChR MG. MG patients are subclassified based on autoantibodies, age at onset, thymus abnormalities, and clinical symptoms. Like

\section{KARGER 125}

E-Mail karger@karger.com www.karger.com/ned
Marion I. Boldingh

Department of Neurology

Oslo University Hospital

Ullevål, PB 4950 Nydalen, NO-0424 Oslo (Norway)

E-Mail marbol@ous-hf.no 
Fig. 1. Flowchart of recruitment with sex and age summary of the populations.

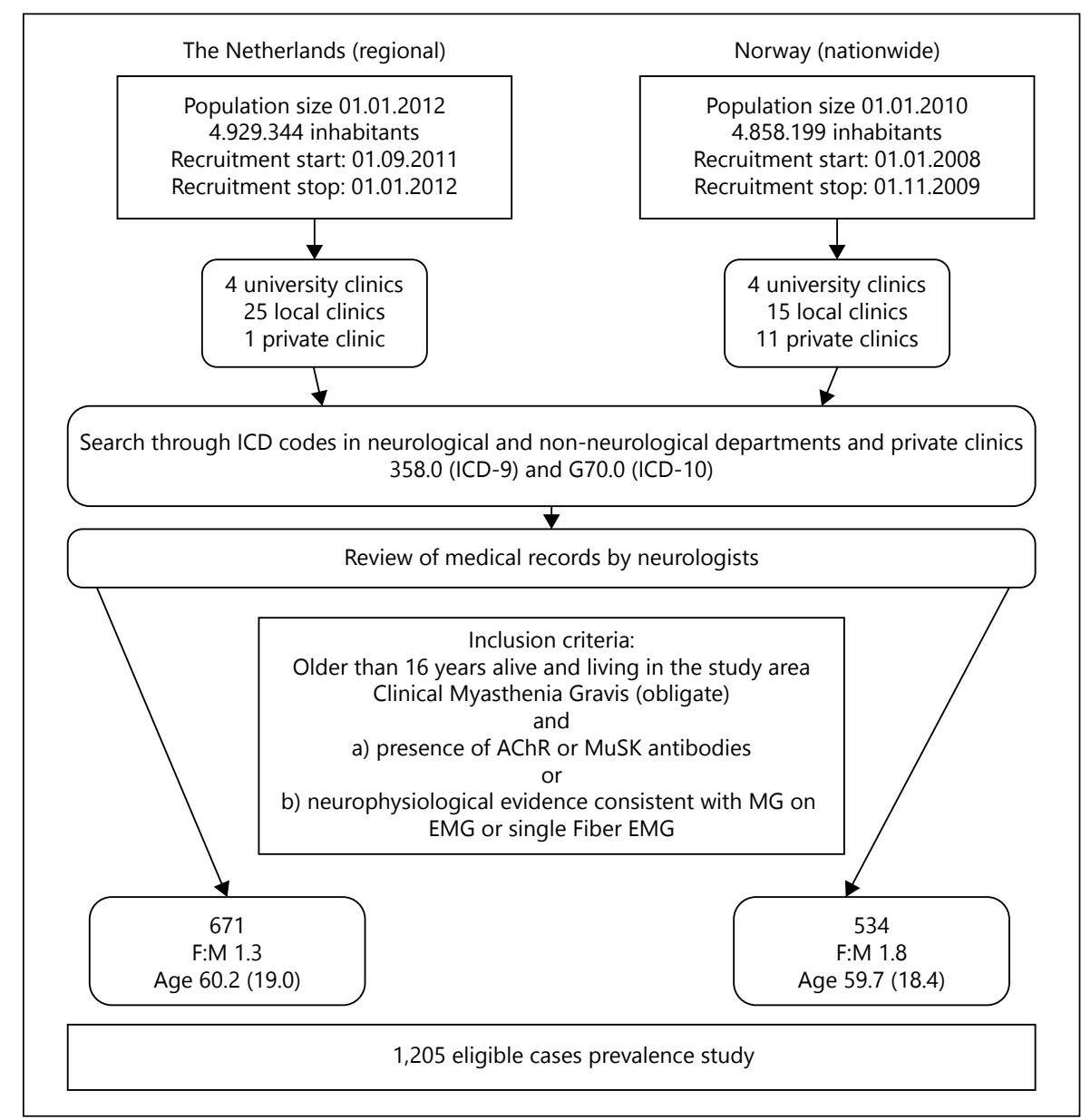

many autoimmune diseases, the etiology is considered multifactorial. Environmental factors as well as genetic risk factors may contribute to the pathogenesis [9]. Variations in geographical prevalence rates can give clues for understanding the disease etiology.

Prevalence and incidence estimates of MG vary across Europe for AChR MG. The differences are partly explained by methodological differences, such as case finding strategies, inclusion criteria, diagnostic facilities, and the way data are presented. However, findings such as female predominance and increasing incidence of late-onset MG (LOMG) are persistent worldwide [10-13]. Previous studies postulate a latitudinal north-south gradient of the MuSK MG prevalence in Europe, being low in the north and higher in the Mediterranean countries [14-18]. However, the only two population-based studies calculating the prevalence of MuSK MG do not show a difference between the Mediterranean country of Greece and the Netherlands in northern Europe $[16,19]$. The prevalence of the other subgroups; such as thymoma MG and seronegative MG (no an- tibodies identified) are difficult to compare due to the divergent methods of patient identification and inclusion [20].

How the prevalence and clinical presentation of the MG subgroups differ geographically has not been examined in the same study in Europe, and interstudy comparisons are hampered by the use of different methods. The aim of the study was to compare the prevalence of MG subgroups between two northern European countries using uniform inclusion criteria and case identification methods. This study was specifically designed to explore these geographical differences and enable valid comparisons between two population-based cohorts.

\section{Materials and Methods}

\section{Patients and Case-Finding Strategy}

We identified living MG patients $>16$ years of age from across the whole of Norway and a contiguous region in the Netherlands using the same case identification methods and 'definite' inclusion criteria (flowchart; fig. 1). The study design was cross-sectional and 
in accordance with the STROBE guidelines [21]. All departments of Neurology were asked to perform a computer search in the hospital electronic coding systems, using the international classification system for diseases (ICD-9 358.0 and ICD-10 G70.0) for MG. The search was dated 20 years back, in time, in both countries to ensure a complete and good representation across age groups and different subgroups. We covered all hospitals in Norway, but in the Dutch study region, data from four local hospitals were not available. These four hospitals were only able to provide an estimate. This number was verified by checking for duplicates. In both the countries, incident cases were referred from other hospitals during the study period and an updated search for incident cases was performed in the first two included hospitals (Oslo University Hospital, Norway and Leiden University Medical Center, the Netherlands). The mean number from the updated search and new referrals in the study area was $5 / \mathrm{million} /$ year in the Netherlands and $4 /$ million/year in Norway. The length of the inclusion period differed, thus there may still be more missed newly diagnosed MG patients from Norway, assuming that not all newly diagnosed MG patients were referred during the study period. We estimate a maximum of 60 missed patients (40 in Norway and 20 in the Netherlands).

\section{Case Verification}

The methods of the Norwegian study are described extensively in two previous reports $[22,23]$. One main investigator (A.H.M.) reviewed the medical records to evaluate whether the patients fulfilled the inclusion criteria. Retrospectively, the clinical variables were collected from patients who gave informed consent by A.H.M., M.I.B., or by collaborating neurologists.

In the Netherlands, the case verification was done by M.I.B. and L.D. Clinical data were collected at the same time as the verification.

\section{Clinical Data}

Demographic data included age, sex, age of onset, diagnostics (antibody status, results from EMG/SF-EMG), phenotype of MG, medication (present use, previous use, or never used), the history of thymectomy and histology, and the occurrence of other autoimmune disorders.

\section{Definitions}

Age onset: age at the first, positive convincing MG symptom was defined as the age of onset. The cases were divided into earlyonset $\mathrm{MG}$ (EOMG $<50$ years of age) and LOMG ( $\geq 50$ years of age), as recommended $[24,25]$. Cases with onset before $<16$ years of age were defined as JMG, but included in the analysis of EOMG since they are clinically very similar to this subtype. The clinical phenotype was categorized into ocular, bulbar, and generalized symptoms. For this variable, we applied a minimum of 2 years of observation, since most patients start with ocular symptoms, but develop generalized symptoms within 2 years [26].

\section{Study Area Norway}

On January 1, 2010, Norway had a population of 4,858,199 inhabitants; out of which $79.8 \%(3,876,857)$ were $\geq 16$ years of age and $11.3 \%$ had a foreign background (www.ssb.no/tabell/05183).

\section{Study Area The Netherlands}

The Dutch cohort derived from all counties of the province of South Holland and 11 counties of the province of North Holland (including the following municipalities: Aalsmeer, Amstelveen,
Amsterdam, Bloemendaal, Diemen, Haarlem, Haarlemmerliede en Spaarnewoude, Haarlemmermeer, Heemstede, Muiden, Ouder-Amstel, Uithoorn, Weesp, and Zandvoort) and included patients identified in two earlier studies on MG epidemiology $[5,16]$. The geographic affiliation of patients was defined by using the patients' postal code during the study period. On January 1, 2012, the Dutch study region had 4,929,344 inhabitants, of which $81.3 \%$ $(4,008,481)$ were $\geq 16$ years of age and $31 \%$ had a foreign background (www.Cbs.nl; http://bit.ly/1CAwW7n).

\section{Standard Protocol Approvals, Registrations, and Patient}

\section{Consents}

The study received an approval from the regional ethical committee (REK) of South-East Norway, the ethical committee of the Leiden University Medical Centre (LUMC), and the Medical Ethical Review Board (METC) South-West Holland in the Netherlands. All clinical data were collected according to the local ethical regulations and informed patient consents.

\section{Statistical Analyses}

The crude rates and age- and gender-specific prevalence rates were calculated for the population over 16 years of age using denominators derived from Statistics Norway (www.ssb.no/tabell/ 10211) and Statistics Netherlands (www.cbs.nl; http://bit.ly/ 1 ANQVyP). We chose the mid population 2009-2010 for Norway and 2011-2012 for the study area in the Netherlands. Up to $95 \%$ confidence intervals (CI) were calculated for rates using Poisson's distribution. We compared the cohorts by prevalence rates, rateratio calculations, and standardization using the European standard population (http://www.who.int/healthinfo/paper31.pdf). We calculated an expected prevalence rate of AChR MG in Norway on January 1, 2012 using the formula: prevalent cases November 1,2009+ 7.2* per million person years at risk [4] - mortality rate January 1,2009-January 1, 2010. Due to the lack of incidence numbers, we could not calculate an expected prevalence rate of the other subgroups; therefore, we did a robustness analysis. We trimmed the dataset to an overlapping time period (19922008) in both countries. By doing this, we also aimed at reducing bias due to differences by inaccurate ICD-10 registrations during implementation, by different time periods of ICD-10 registration between Norway and the Netherlands, and diagnostic delay. The average population at risk between1992-2008 was used as the denominator. The clinical variables were analyzed using Chi-square tests for categorical data and Student t-tests for continuous data. A $p$ value of $<0.05$ was considered significant for all analyses. The statistics were performed using SPSS 22.0 (IBM SPSS, Chicago, Ill., USA), STATA 14, (StataCorp, Tex., USA), and Episheet (krothman.hostbyet2.com).

\section{Results}

\section{Prevalence Estimates}

Characteristics of the 1,205 MG patients, of whom 534 were Norwegian (63.9\% females) and 671 Dutch $(55.9 \%$ females), are shown in table 1. Age- and sex-adjusted prevalence rates are shown in figure 2 and tables 2 and 3. There was no AChR latitudinal north-south prevalence 
Table 1. Clinical characteristics of the myasthenia gravis patients

$\begin{array}{llll}\begin{array}{l}\text { Information from total } \\ \text { cohort, all patients }(\mathrm{n}=1,205)\end{array} & \begin{array}{l}\text { The Netherlands } \\ (\mathrm{n}=671)\end{array} & \begin{array}{l}\text { Norway } \\ (\mathrm{n}=534)\end{array}\end{array} \quad{\mathrm{p} \mathrm{value}{ }^{2}}^{2}$

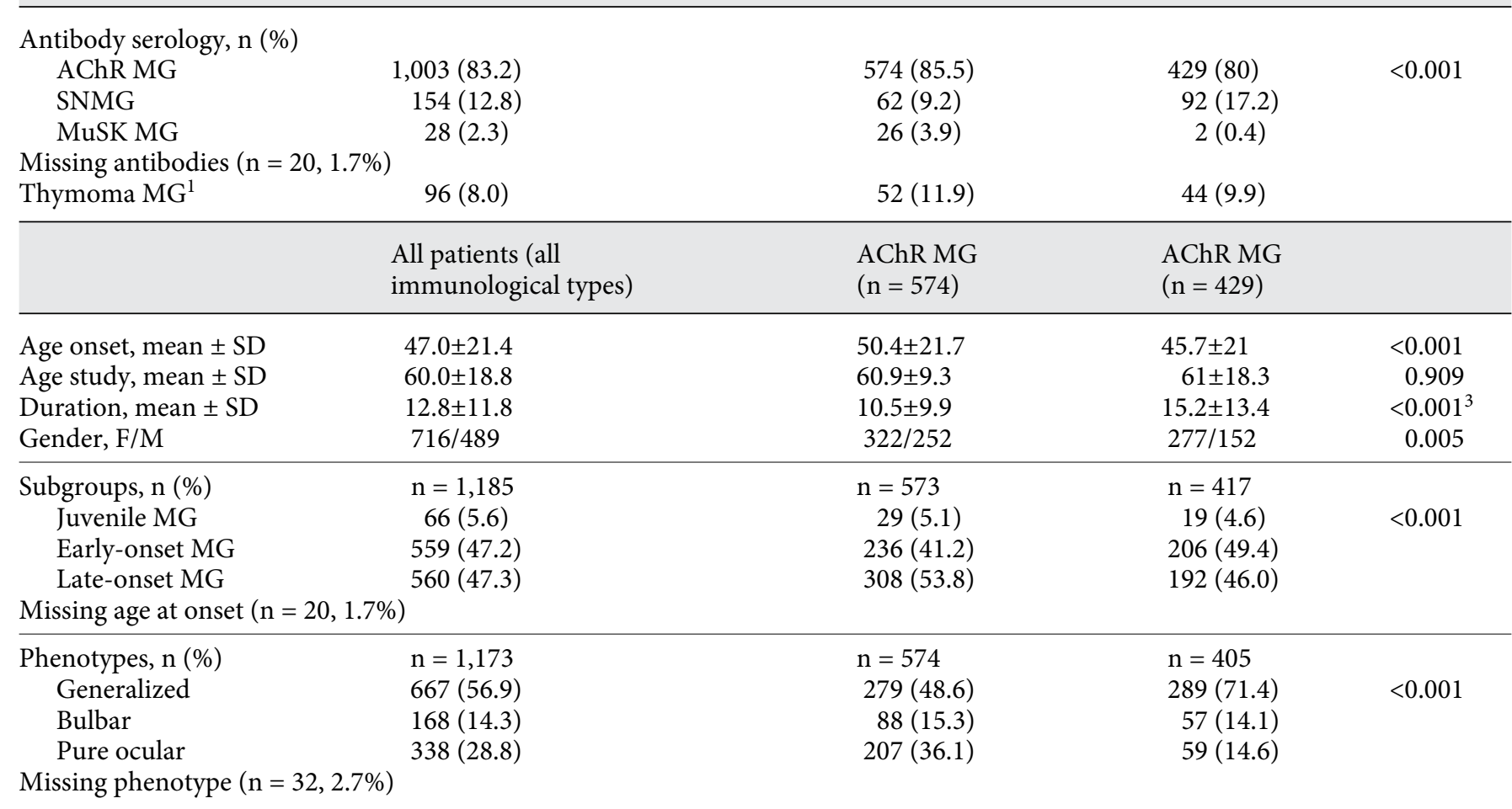

AChR MG = Presence of acetylcholine receptor antibodies; SNMG = seronegative MG; MuSK MG = presence of muscle-specific kinase antibodies; JMG = juvenile MG ( $<15$ years); EOMG = early-onset MG ( $<50$ years); LOMG = late-onset MG ( $\geq 50$ years).

${ }^{1}$ Thymoma MG: all except four had AChR antibodies (2 were SNMG and 2 had unknown antibodies).

${ }^{2} \mathrm{p}$ value was calculated for difference between the countries for (a) total cohort and (b) AChR MG. The p value is adjusted for age and sex by linear and logistic regression analysis.
${ }^{3} \mathrm{p}$ value for disease duration was significantly different for females 0.001 because of an outlier in Norway. The longest follow-up was 71 years for a Norwegian female patient, diagnosed in 1938, 17 years old, today 88 years. In the Netherlands, the longest followup was 60 years, a patient diagnosed in 1952, 15 years old, and is today 75 years old. Among the males, there were no differences in disease duration between the countries. The longest follow-up was 50 years, diagnosed in 1959 and in the Netherlands 56 years, diagnosed in 1956. difference within Norway. The mean prevalence in the two most north counties (Finnmark and Troms, latitude $71-69^{\circ} \mathrm{N}$ ) and the three most southern counties (Rogaland, Aust-and Vest Agder, latitude $58^{\circ} \mathrm{N}$ ) was 98 (95\% CI 58-155) and 107 (95\% CI 81-131), respectively.

\section{Age at Onset, Gender, and Phenotypes}

The Dutch cohort had a higher mean age at onset compared to the Norwegian patients $(50.3 \pm 21.8$ vs. $45.1 \pm$ 20.9 , adjusted $\mathrm{p}<0.001)$. The mean age at onset was higher in the AChR MG and SNMG subgroups in the Netherlands (illustrated in fig. 3).

In both countries, women were affected 2-5 times more often than men up to the age of 60 . In Norway, MG in females was slightly more prevalent than in males until the age of 80 , whereas in the Netherlands, males were more prevalent already from 60 years of age (table 3 ). The frequency of elderly onset MG (onset after 60 years of age) was $25 \%$ in the Norwegian cohort and $39 \%$ in the Dutch cohort, thus 1.5-fold more.

Phenotypically, there were more ocular (RR 2.4 (1.73.5)) and bulbar symptoms (RR $1.7(1.1-2.8))(\mathrm{p}<0.05)$ in the Dutch LOMG patients than in the Norwegian LOMG patients. There were no differences in the prevalence of the various phenotypes among EOMG between the countries.

The Expected AChR MG Prevalence, Robustness Anal$y$ sis, and Standardization. 429 prevalent cases $+7.2^{*}$ 


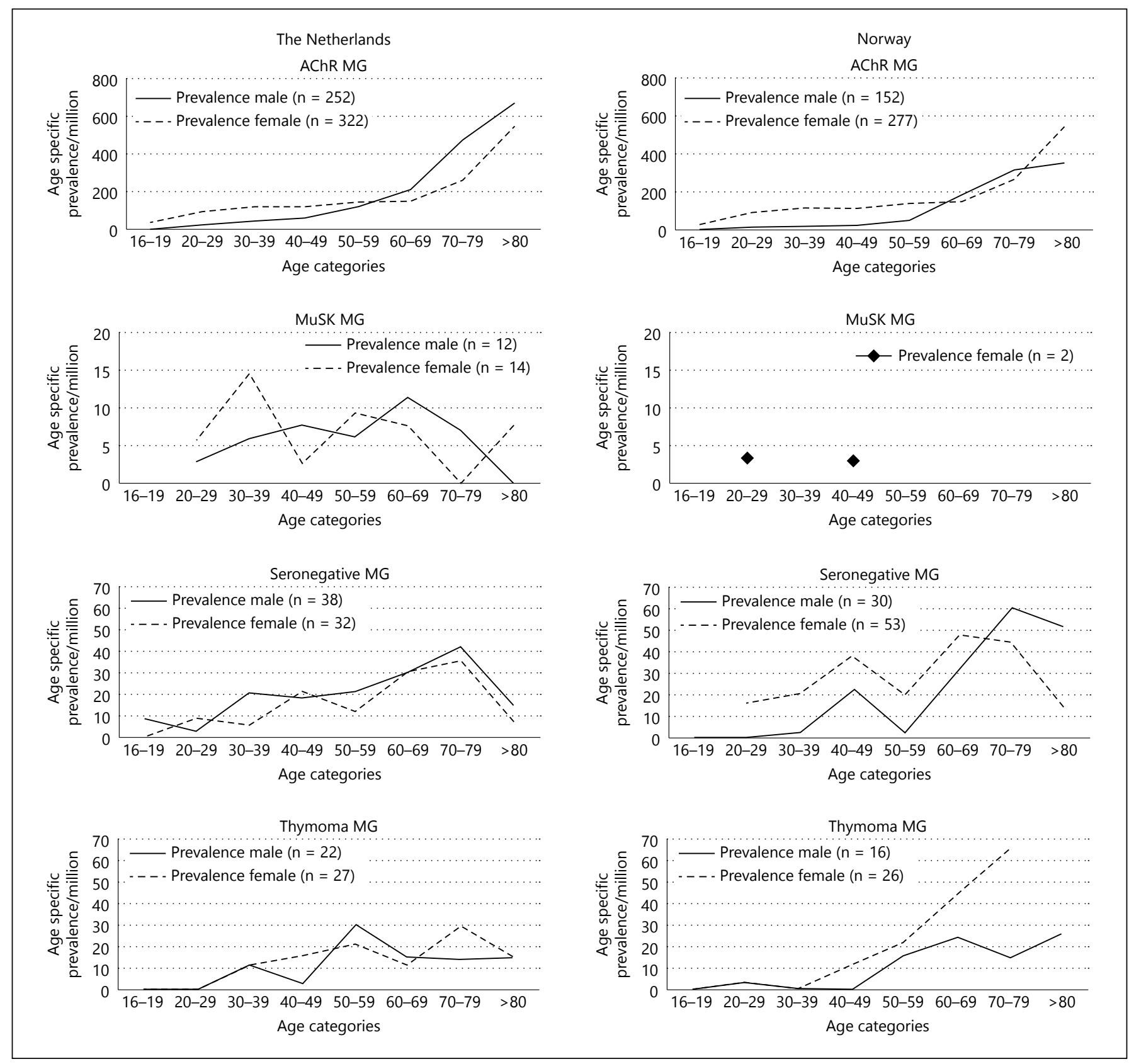

Fig. 2. Prevalence of MG serological subgroups in the Netherlands and Norway. Figure illustrates the gender-specific prevalence of MG serological subgroups. The prevalence rate of AChR MG and MuSK MG were higher in the Dutch cohort compared to the

Norwegian cohort. There were no differences between the seronegative MG or MG associated with thymoma. The exact number for the crude prevalence and European standard rate are given in table 2 .

7,931,304/million - 32 expected deaths among the MG patients $=454$ stipulated AChR MG cases in Norway on January 1, 2012, which leads to an expected AChR MG prevalence rate of 114 (95\% CI 103-124), still significantly different from what the AChR MG prevalence was in the Dutch study region. The robustness

analysis included 311 Dutch and 247 Norwegian MG patients. All results were verified in this analysis, except for the result of more LOMG males in the Netherlands compared to Norway. Standardization to European standard population confirmed the same differences. 
Table 2. Prevalence estimates of the MG populations

\begin{tabular}{|c|c|c|c|c|}
\hline & \multicolumn{2}{|l|}{ The Netherlands } & \multicolumn{2}{|l|}{ Norway } \\
\hline & $\begin{array}{l}\text { rate per million } \\
(95 \% \mathrm{CI})\end{array}$ & $\begin{array}{l}\text { European standard } \\
\text { rate }(95 \% \mathrm{CI})\end{array}$ & $\begin{array}{l}\text { rate per million } \\
(95 \% \mathrm{CI})\end{array}$ & $\begin{array}{l}\text { European standard } \\
\text { rate }(95 \% \mathrm{CI})\end{array}$ \\
\hline Overall $\mathrm{MG}^{*}$ & $167(155-180)$ & $110(104-132)$ & $138(126-150)$ & $97(88-100)$ \\
\hline \multicolumn{5}{|l|}{ Sex } \\
\hline Men* & $151(134-169)$ & $111(93-120)$ & $80(69-92)$ & $71(61-81)$ \\
\hline Women & $183(165-203)$ & $120(110-140)$ & $174(157-203)$ & $120(110-140)$ \\
\hline \multicolumn{5}{|l|}{ Age, years } \\
\hline $16-19$ & $18(5-10)$ & & $27(11-56)$ & \\
\hline $20-29$ & $70(52-132)$ & & $55(38-77)$ & \\
\hline $30-39$ & $95(74-143)$ & & $72(53-95)$ & \\
\hline $40-49$ & $116(94-195)$ & & $94(72-119)$ & \\
\hline $50-59$ & $148(120-227)$ & & $121(95-152)$ & \\
\hline $60-69$ & $226(187-270)$ & & $234(194-218)$ & \\
\hline $70-79$ & $417(348-548)$ & & $404(338-489)$ & \\
\hline$>80$ & $635(529-757)$ & & $327(256-412)$ & \\
\hline \multicolumn{5}{|l|}{ Antibodies } \\
\hline AChR MG* & $143(131-155)$ & $96(88-100)$ & $111(100-122)$ & $76(69-84)$ \\
\hline SNMG & $15(11-19)$ & $15(8-13)$ & $24(19-29)$ & $18(8-13)$ \\
\hline MuSK MG* & $6.5(4-10)$ & $5(3-7)$ & $0.5(0-2)$ & $0.4(0.2-1)$ \\
\hline Thymoma MG & $13(10-17)$ & $10(7-12)$ & $11(8-15)$ & $8(6-10)$ \\
\hline \multicolumn{5}{|c|}{ Age at onset (non-thymoma) } \\
\hline EOMG & $125(111-140)$ & 89 (79-98) & $131(116-147)$ & $93(82-100)$ \\
\hline $\mathrm{LOMG}^{*}$ & $193(173-216)$ & $190(170-210)$ & $128(111-147)$ & $130(110-150)$ \\
\hline \multicolumn{5}{|l|}{ Phenotype } \\
\hline Ocular $\mathrm{MG}^{*}$ & $62(54-70)$ & $41(35-46)$ & $24(19-29)$ & $17(13-20)$ \\
\hline Bulbar MG & $25(20-30)$ & $15(12-18)$ & $18(14-22)$ & $12(9-15)$ \\
\hline Generalized MG & $81(72-90)$ & $58(52-65)$ & $88(79-98)$ & $62(56-69)$ \\
\hline
\end{tabular}

\section{Discussion}

This population-based study of two North-European countries clearly describes a novel north-south gradient for AChR MG and confirms a north-south gradient for MuSK MG. Moreover, there were 1.5-fold more late-onset patients in the Netherlands and phenotypically, they were less likely to generalize from ocular symptoms.

The validity of the study relies on the completeness and comparability of the two cohorts. Both the cohorts were population-based and systematically collected over well-defined geographical areas. Much effort was put into the design and recruitment, making sure that the cohorts were comparable in the study. We minimized the selection bias through the use of the same inclusion criteria, search strategies, and a limited number of investigators. Also, the same methods were used for AChR and MuSK assays; all utilizing the conventional radio immuno precipitation assay with $\geq 0.4 \mathrm{nmol} / \mathrm{l}$ as the cutoff for AChR antibodies and $0.05 \mathrm{nmol} / \mathrm{l}$ for MuSK antibodies.
We believe that the countries are comparable when it comes to accessibility to a neurologist and to diagnostics, since they both have well-functioning health care systems. On one hand, the different prevalence rates could be explained by differences in the underlying population, such as longevity, birth and death rates. However, the age distributions of the geographical areas were not marked different. Norway had a 1-2-year longer life expectancy, but similar birth and death rates as the Netherlands. Thus, since the differences remained after standardization to the European standard population, a method to control for underlying population differences and the robustness analysis, we believe we have documented a real geographical gradient of AChR MG and MuSK MG between Norway and the Netherlands.

An AChR MG south-north gradient was hypothesized in an Australian epidemiological study [27] through indirect comparisons. In Europe, the highest prevalence rate is reported from Serbia (317/million inhabitants) and Spain (328/million inhabitants) and the highest an- 
Table 3. Gender-specific prevalence rates

\begin{tabular}{|c|c|c|c|c|c|c|c|c|}
\hline & \multicolumn{4}{|c|}{ The Netherlands } & \multicolumn{4}{|l|}{ Norway } \\
\hline & population & cases & rate/million & $95 \% \mathrm{CI}$ & population & cases & rate/million & $95 \% \mathrm{CI}$ \\
\hline \multicolumn{9}{|c|}{ Males, years } \\
\hline $16-19$ & 116,641 & 0 & 0 & & 132,422 & 1 & 8 & $0-42$ \\
\hline $20-29$ & 332,624 & 9 & 27 & $12-51$ & 307,672 & 6 & 20 & $7-42$ \\
\hline $30-39$ & 336,526 & 17 & 51 & $29-81$ & 346,936 & 15 & 43 & $24-71$ \\
\hline $60-69$ & 260,859 & 67 & 257 & $199-326$ & 246,606 & 54 & 219 & $165-286$ \\
\hline $70-79$ & 140,800 & 77 & 547 & $432-684$ & 131,485 & 50 & 380 & $282-501$ \\
\hline$>80$ & 67,284 & 50 & 743 & $552-980$ & 77,172 & 30 & 389 & $262-555$ \\
\hline All ages & $1,962,510$ & 296 & 151 & $134-169$ & $1,909,738$ & 193 & 101 & 88-116 \\
\hline \multicolumn{9}{|c|}{ Females, years } \\
\hline $50-59$ & 323,278 & 54 & 167 & $126-218$ & 300,500 & 52 & 173 & $129-227$ \\
\hline $60-69$ & 262,164 & 51 & 195 & $145-256$ & 247,833 & 62 & 250 & $192-321$ \\
\hline $70-79$ & 166,290 & 51 & 307 & $228-403$ & 157,416 & 68 & 432 & $335-548$ \\
\hline$>80$ & 129,457 & 75 & 579 & $456-726$ & 142,656 & 42 & 294 & $212-398$ \\
\hline All ages & $2,045,971$ & 375 & 183 & $165-203$ & $1,940,765$ & 341 & 176 & $157-203$ \\
\hline
\end{tabular}

The table shows age- and gender-specific prevalence rates per million inhabitants. 95\% CI calculated by Poissons distribution.

nual incidence rate from Spain (21/million inhabitants) $[2,11,28]$. When reviewing population-based European MG prevalence studies from the latest decade, one could suspect lower prevalence rates in northern Europe [1] than southern Europe $[3,28]$, but the assessments are hampered by a lack of uniformity of inclusion criteria and small sample sizes. There was no evidence for a latitudinal prevalence difference within Norway, stretching from $71^{\circ} \mathrm{N}$ in the north to $58^{\circ} \mathrm{N}$ in the south, a distance longer than from the south of Norway to the Netherlands, $51^{\circ} \mathrm{N}$. These results are in accordance with epidemiological studies performed in Norway last decade $[23,29,30]$.

The prevalence rates are rising all over Europe and this appears to concern mostly the elderly onset MG (over the age of 65-70) [10-12]. In the Dutch MG population, we confirmed a rise in occurrence in the elderly in the Netherlands compared to a study from the same area 10 years ago [5]. Two repetitive populationbased studies are inconclusive regarding whether the late-onset subgroup really is rising $[10,31,32]$ and claim that it most certainly is due to an increased awareness of MG in the elderly and better diagnostics and casefinding methods. We have controlled the typical meth- odological bias in our study and found more LOMG in the Netherlands than in Norway. Our findings give support for the genetic or environmental influence, instead of the methodological.

The MuSK MG prevalence difference of 0.5 vs. 6.5/ million inhabitants confirms the hypothesized MuSK MG difference between Norway (north) and the Netherlands (south) in northern Europe. Up to this date, there were only two population-based prevalence studies of MuSK MG in Europe; one from the Netherlands (2.8/ million, 2004) [16] and one from Greece (2.9/million, 2006) [19], with pretty similar prevalence numbers. There is, however, a consistent trend toward more MuSK MG patients in the seronegative cohorts at southern latitudes, which support our findings. Our finding of only two MuSK MG patients in Norway is consistent with the report of zero Norwegian MuSK MG patients by Romi et al. in a case series of 19 seronegative MG patients [14]. The increase in MuSK prevalence in the Netherlands from 2.8 in 2004 to 6.5 in 2012 cannot be explained by incident cases and longevity alone [16]. Most likely, this increase is due to an extended knowledge and availability of the MuSK antibody assay in the Netherlands since 2004. 


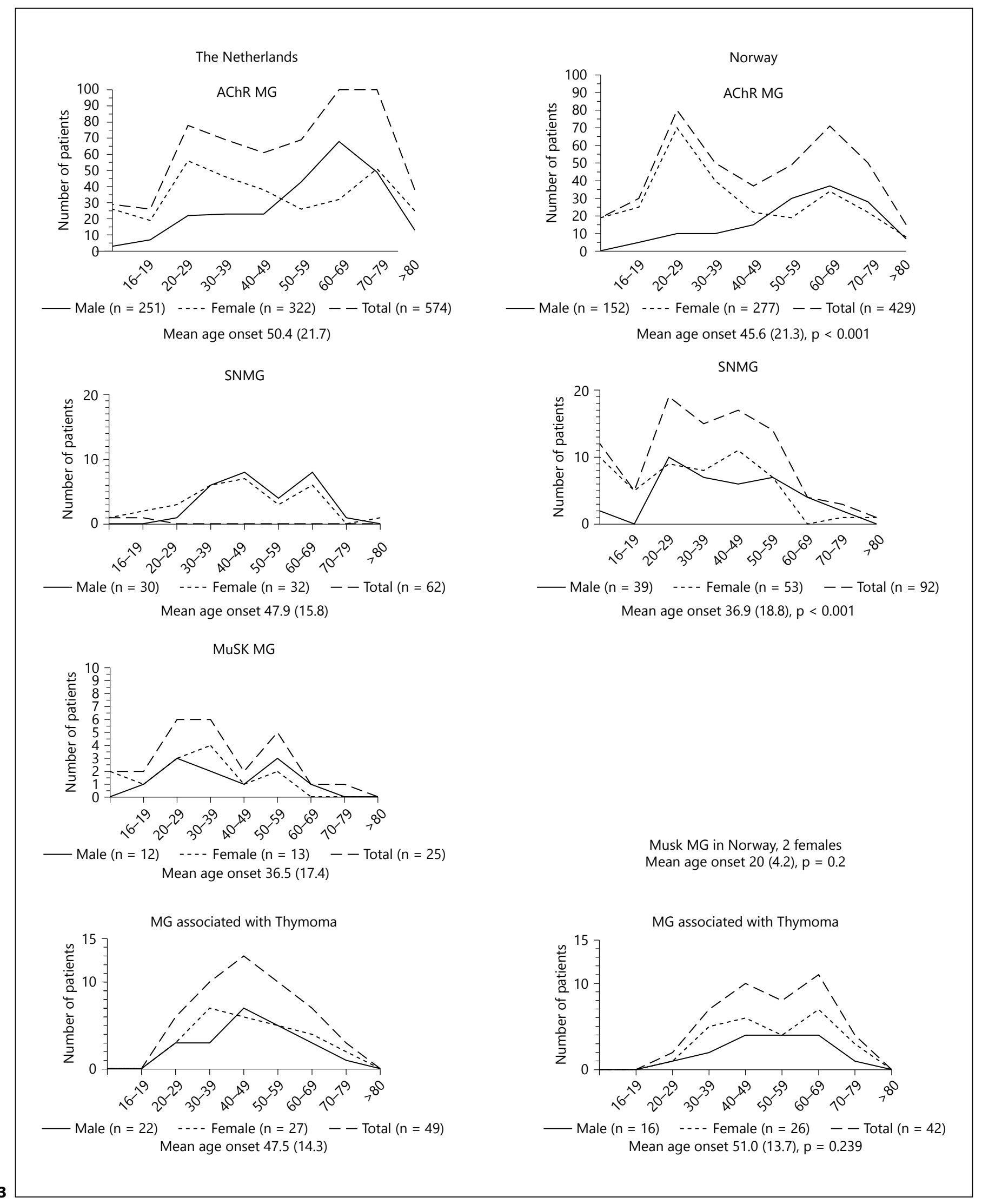

(For legend see next page.) 
We did not find any prevalence or clinical differences in thymoma MG between the Norway and the Netherlands. Thymoma occurrence rates were similar to other population-based studies in northern as well as in southern Europe, estimated to be around 10\% [2, 3, 33]. The prevalence rate found is exactly the same as it was in the Netherlands in 2000 [5]. Thus, we cannot support the theory of an increasing incidence of thymoma $M G$ in Europe [34].

An intriguing and unexpected finding was that there was more purely ocular MG among LOMG patients in the Netherlands compared to Norway. We believe that the difference is not due to bias, since the distribution of ocular and bulbar versus the generalized symptoms EOMG was similar in both countries. One may speculate whether this difference derives from treatment differences between the two cohorts, such as early treatment with corticosteroids in purely ocular-manifested MG, thereby preventing conversion to a generalized disease [35]. On the other hand, variable frequencies for ocular MG are described around Europe (13-52\%) [3, 25].

This particular region of the Netherlands is multiethnic (30\% with other ethnic backgrounds than Dutch) and as a consequence, more heterogeneous when it comes to the genetic susceptibility for MG than Norway. Norway is a relatively homogenous population, except from the aboriginal Sami population in the North, which have a different human leucocyte antigen profile and are proven less prone for autoimmune disorders like multiple sclerosis (MS) and Bechterews [36, 37]. Results from genomewide association studies are divergent, both regarding associations within the HLA loci as well as non-HLA alleles across populations $[38,39]$. There are reports that suggest other variants of associated HLA in AChR MG vs. MuSK MG, LOMG vs. EOMG, and ocular MG vs. generalized MG [22, 40-42]. Renton et al. calculated heritability estimates; thus, the proportion of disease that arises from genetics were found to be around $35-37 \%$ for early- and late-onset MG [39], pretty similar to calculations from twin studies [9]. These types of data have been used to argument that environmental factors play a major role in causing the disease [43].

Fig. 3. Shows age at onset in the different subgroups. The bimodal distribution for AChR MG peaks for females in the age group 20-29 in both countries and for males in the age group 60-69. The mean age of onset was later in the late-onset group in the Netherlands, 68 years (9.8) vs. 65 years (9.5), $\mathrm{p}<0.001$, but was similar for EOMG,

Geographical Distribution of Myasthenia Gravis
A latitudinal north-south gradient is described for many other autoimmune disorders, like MS, irritable bowel syndrome, and diabetes type 1 . In these diseases, a higher prevalence is observed in industrialized regions with better socioeconomic conditions leading to hypotheses involving the western life style, among others vitamin D levels, nutrition, and hygiene [44]. These factors are not likely to differ between Norway and the Netherlands, except for the industrialization grade. The studied area in the Netherlands is characterized by a high population density and urbanity, with large cities and an airport. Two recent studies examining the geographical variation have found more prevalent MG cases in the urban areas compared to the rural areas $[2,45]$. One could speculate whether the urban differences reflect individual behavior or exposure of exogenous environmental factors like, for example, air pollution influencing the disease development. Another difference is latitudinal differences, which leads to a colder climate in the north and less sunlight during wintertime. Less sunlight can lead to lower vitamin D levels and are highly debated as a modulating factor in MS [46]. Since we found the opposite latitudinal gradient as observed in the MS prevalence research and no evidence of latitudinal difference within Norway, this may indicate that the sunlight and climatic differences between Norway and the Netherlands do not play a major role in the disease risk in MG.

The main strength of the study is the large sample size and the comparability of the two cohorts. Since the aim of the study was to compare two cohorts, we used a single source (ICD-10 codes) and strict criteria for evaluating definite MG. As a consequence, we excluded probable MG patients with only a positive edrophonium test. This increased our case ascertainment and comparability, but may underestimate the prevalence compared to many studies. Patient registries, like ICD-10, are considered the most sensitive way of identifying patients [47]. The medical chart and laboratory confirmation exclude falsepositive MG patients [1]. There may be missed patients due to inaccurate registrations before 1990, those currently under diagnostic work-up in both countries, and incident cases after registration. We did an updated ICD search in the first included hospitals and included all

29.4 years (11.2) vs. 27 years (9.9). The mean age at onset in the Dutch early-onset MuSK MG was 31.1 (9.5) and for the late-onset MuSK MG was 59.1 (8.5). A bimodal distribution is less evident within the seronegative group. The onset occurred later for seronegative EOMG in the Netherlands, 36.4 years (10) vs. 29.3 years (13). 
new referrals to limit this inclusion bias. However, since the length of inclusion was longer in Norway than in the Netherlands ( 1.5 years vs. 4 months), there may be more newly diagnosed cases missed in Norway. In the Netherlands, we might also have missed patients who are resident in the region, but receive treatment from a hospital outside the region and from the lacking four hospitals. We did not include patients only known to primary care. This was due to practical reasons. MG is a rare disease and diagnostic work-up and treatment are in almost all cases performed by neurologists. Regarding this issue, there is no reason to believe that there are differences between the countries. The study was performed 2 years apart; since prevalence is an accumulated number, this may have caused a bias. We aimed at reducing this by performing the same length of search, 20 years back in time. We did two subanalyses for verification; (a) an expected prevalence if the point prevalence date was January 1, 2012 in Norway and (b) a robustness analysis. The expected AChR MG prevalence as on January 1, 2012 in Norway was 113 (95\% CI 103-155) and comparable to 115.5 (95\% CI 106.1-125.7) from January 1, 2008 [4], thus indicating little fluctuation in the AChR MG prevalence in Norway and a limited impact of having studied the cohorts 2 years apart. We could not confirm more prevalent $\mathrm{AChR}$ late-onset males in the robustness analysis. Studying the populations 2 years apart may partly account for this, since the incidence of LOMG is considerably higher than for EOMG (34 vs. 7) and the mortality rates too, leading to less stability of the prevalence measurement.

To conclude, we showed a geographical prevalence difference of AChR MG between two European countries of different latitude, which is a novel finding, and confirmed the hypothesized latitudinal gradient of MuSK MG. This geographical variation is likely to reflect the gene-environmental interaction in the disease etiology of MG.

\section{Acknowledgment}

We are grateful to all participating neurological departments in Norway and the Netherlands (co-investigator appendix). We would like to thank all MG patients for their participation. We are grateful to M. Elverhøy and S.P. Henriksen (technical assistance), J. Owe and K. de Klerk (collecting data), E. Tallaksen (copyediting), and the collaborators within the FIGHT-MG project.

\section{Funding}

This project was mainly supported by FIGHT-MG EU FP7 frame program grant no. 242210 (to M.I.B.) and Euromyasthenia EU FP7 no. 2005105 (to A.H.M.), by grants from Unifor.no, Valsøe's foundation, Wilhelmsen's foundation, the Norwegian association for patients with muscle disease, Princes Beatrix foundation, and the Association Francaise contre les Myopathies.

\section{Contributors Statement}

Dr. M.I. Boldingh designed and conceptualized the study, analyzed and interpreted the data, and drafted and revised the article. Dr. A.H. Maniaol designed and conceptualized the study, analyzed and interpreted the data, and revised the article. C. Brunborg performed the statistical analysis and interpretation and revised the article. L. Dekker, Dr. A.F. Lipka, Dr. T.H. Popperud, Dr. E.H. Niks, and Dr. A.T. Heldal acquired the clinical data and revised the article. Prof. J.J.G.M. Verschuuren designed the study, analyzed, interpreted the data, and drafted and revised the article. Prof. C.M.E. Tallaksen initiated the project, designed the study, analyzed and interpreted the data, and drafted and revised the article.

\section{Conflicts of Interests}

Dr. M.I. Boldingh, Dr. A.H. Maniaol, C. Brunborg, L. Dekker, Dr. A.T. Heldal, Dr. A.F. Lipka, Dr. T.H. Popperud, Dr. E.H. Niks, and Prof. C.M.E. Tallaksen report no disclosures. Dr. J.J.G.M. Verschuuren was involved in the thymectomy trial, sponsored by $\mathrm{NIH}$, and in a FP7 HEALTH-2013-INNOVATION-1, European grant number 602420 on MG. The Neurology department of the LUMC has received royalties from antibody tests. J.J.G.M. Verschuuren did not receive any personal payments.

\section{References}

1 Oöpik M, Puksa L, Lüüs SM, Kaasik AE, Jakobsen J: Clinical and laboratory-reconfirmed myasthenia gravis: a population-based study. Eur J Neurol 2008;15:246-252.

2 Montomoli C, Citterio A, Piccolo G, Cioccale R, Ferretti VV, Fratti C, et al: Epidemiology and geographical variation of myasthenia gravis in the province of Pavia, Italy. Neuroepidemiology 2012;38:100-105.

3 Lavrnic D, Basta I, Rakocevic-Stojanovic V, Stevic Z, Peric S, Nikolic A, et al: Epidemiological study of adult-onset myasthenia gravis in the area of Belgrade (Serbia) in the period 19792008. Neuroepidemiology 2013;40:190-194.

4 Heldal AT, Owe JF, Gilhus NE, Romi F: Seropositive myasthenia gravis: a nationwide epidemiologic study. Neurology 2009;73:150151.

5 Wirtz PW, Nijnuis MG, Sotodeh M, Willems LN, Brahim JJ, Putter H, et al: The epidemiology of myasthenia gravis, Lambert-Eaton myasthenic syndrome and their associated tu- mours in the northern part of the province of South Holland. J Neurol 2003;250:698-701.

6 Pallaver F, Riviera AP, Piffer S, Ricciardi R: Change in myasthenia gravis epidemiology in Trento, Italy, after twenty years. Neuroepidemiology 2011;36:282-287.

7 Vincent A, Newsom-Davis J: Acetylcholine receptor antibody as a diagnostic test for myasthenia gravis: results in 153 validated cases and 2967 diagnostic assays. J Neurol Neurosurg Psychiatry 1985;48:1246-1252. 
8 Vincent A, Leite MI, Farrugia ME, Jacob S, Viegas S, Shiraishi H, et al: Myasthenia gravis seronegative for acetylcholine receptor antibodies. Ann N Y Acad Sci 2008;1132. 84-92.

9 Ramanujam R, Pirskanen R, Ramanujam S, Hammarström L: Utilizing twins concordance rates to infer the predisposition to myasthenia gravis. Twin Res Hum Genet 2011; 14:129-136.

10 Somnier FE: Increasing incidence of late-onset anti-AChR antibody-seropositive myasthenia gravis. Neurology 2005;65:928-930.

11 Aragonès JM, Bolíbar I, Bonfill X, Bufill E, Mummany A, Alonso F, et al: Myasthenia gravis: a higher than expected incidence in the elderly. Neurology 2003;60:1024-1026.

12 Casetta I, Groppo E, De Gennaro R, Cesnik E, Piccolo L, Volpato S, et al: Myasthenia gravis: a changing pattern of incidence. J Neurol 2010;257:2015-2019.

13 Murai H, Yamashita N, Watanabe M, Nomura Y, Motomura M, Yoshikawa H, et al: Characteristics of myasthenia gravis according to onset-age: Japanese nationwide survey. J Neurol Sci 2011;305:97-102.

14 Romi F, Aarli JA, Gilhus NE: Seronegative myasthenia gravis: disease severity and prognosis. Eur J Neurol 2005;12:413-418.

15 Kostera-Pruszczyk A, Kamińska A, Dutkiewicz M, Emeryk-Szajewska B, StrugalskaCynowska MH, Vincent A, et al: MuSK-positive myasthenia gravis is rare in the Polish population. Eur J Neurol 2008;15:720-724.

16 Niks EH, Kuks JB, Verschuuren JJ: Epidemiology of myasthenia gravis with anti-muscle specific kinase antibodies in The Netherlands. J Neurol Neurosurg Psychiatry 2007;78:417418.

17 Padua L, Tonali P, Aprile I, Caliandro P, Bartoccioni E, Evoli A: Seronegative myasthenia gravis: comparison of neurophysiological picture in MuSK+ and MuSK- patients. Eur J Neurol 2006;13:273-276.

18 Lavrnic D, Losen M, Vujic A, De Baets M Hajdukovic LJ, Stojanovic V, et al: The features of myasthenia gravis with autoantibodies to MuSK. J Neurol Neurosurg Psychiatry 2005;76:1099-1102.

19 Tsiamalos P, Kordas G, Kokla A, Poulas K, Tzartos SJ: Epidemiological and immunological profile of muscle-specific kinase myasthenia gravis in Greece. Eur J Neurol 2009;16: 925-930.

20 Carr AS, Cardwell CR, McCarron PO McConville J: A systematic review of population based epidemiological studies in Myasthenia Gravis. BMC Neurol 2010;10:46.

21 von Elm E, Altman DG, Egger M, Pocock SJ, Gøtzsche PC, Vandenbroucke JP: The strengthening the reporting of observational studies in epidemiology (STROBE) statement: guidelines for reporting observational studies. Lancet 2007;370:1453-1457.

22 Maniaol AH, Elsais A, Lorentzen ÅR, Owe JF, Viken MK, Sæther H, et al: Late onset myasthenia gravis is associated with HLA DRB ${ }^{*} 15$ : 01 in the Norwegian population. PLoS One 2012; 7:e36603.

23 Maniaol AH, Boldingh M, Brunborg C, Harbo HF, Tallaksen CM: Smoking and socioeconomic status may affect myasthenia gravis. Eur J Neurol 2013;20:453-460.

24 Gilhus NE: Autoimmune myasthenia gravis. Expert Rev Neurother 2009;9:351-358.

25 Somnier FE, Keiding N, Paulson OB: Epidemiology of myasthenia gravis in Denmark. A longitudinal and comprehensive population survey. Arch Neurol 1991;48:733-739.

26 Grob D, Brunner N, Namba T, Pagala M: Lifetime course of myasthenia gravis. Muscle Nerve 2008;37:141-149.

27 Gattellari M, Goumas C, Worthington JM: A national epidemiological study of Myasthenia Gravis in Australia. Eur J Neurol 2012;19: 1413-1420.

28 Aragonès JM, Altimiras J, Roura P, Alonso F, Bufill E, Munmany A, et al: Prevalence of myasthenia gravis in the Catalan county of Osona. Neurologia 2014;pii:S0213-4853(14) 00203-5.

29 Heldal AT, Eide GE, Gilhus NE, Romi F: Geographical distribution of a seropositive myasthenia gravis population. Muscle Nerve 2012; 45:815-819.

30 Andersen JB, Engeland A, Owe JF, Gilhus NE: Myasthenia gravis requiring pyridostigmine treatment in a national population cohort. Eur J Neurol 2010;17:1445-1450.

31 Andersen JB, Heldal AT, Engeland A, Gilhus NE: Myasthenia gravis epidemiology in a national cohort; combining multiple disease registries. Acta Neurol Scand Suppl 2014;198: 26-31.

32 Pedersen EG, Hallas J, Hansen K, Jensen PE, Gaist D: Late-onset myasthenia not on the increase: a nationwide register study in Denmark, 1996-2009. Eur J Neurol 2013;20 309-314.

33 Robertson NP, Deans J, Compston DA: Myasthenia gravis: a population based epidemiological study in Cambridgeshire, England. J Neurol Neurosurg Psychiatry 1998;65:492-496.

34 Mao ZF, Mo XA, Qin C, Lai YR, Hackett ML Incidence of thymoma in myasthenia gravis: a systematic review. J Clin Neurol 2012;8: 161-169.

35 Zach H, Cetin H, Hilger E, Paul A, Wuschitz $B$, Jung $R$, et al: The effect of early prednisolone treatment on the generalization rate in ocular myasthenia gravis. Eur J Neurol 2013; 20:708-713.
36 Harbo HF, Riccio ME, Lorentzen AR, Utsi E, Myhr KM, Mellgren SI, et al: Norwegian Sami differs significantly from other Norwegians according to their HLA profile. Tissue Antigens 2010;75:207-217.

37 Harbo HF, Utsi E, Lorentzen AR, Kampman MT, Celius EG, Myhr KM, et al: Low frequency of the disease-associated $\mathrm{DRB} 1^{*}$ $15-\mathrm{DQB1}{ }^{*} 06$ haplotype may contribute to the low prevalence of multiple sclerosis in Sami. Tissue Antigens 2007;69:299-304.

38 Gregersen PK, Kosoy R, Lee AT, Lamb J, Sussman J, McKee D, et al: Risk for myasthenia gravis maps to a (151) Pro->Ala change in TNIP1 and to human leukocyte antigenB*08. Ann Neurol 2012;72:927-935.

39 Renton AE, Pliner HA, Provenzano C, Evoli A, Ricciardi R, Nalls MA, et al: A genomewide association study of myasthenia gravis. JAMA Neurol 2015;72:396-404.

40 Kida K, Hayashi M, Yamada I, Matsuda H, Yoshinaga J, Takami S, et al: Heterogeneity in myasthenia gravis: HLA phenotypes and autoantibody responses in ocular and generalized types. Ann Neurol 1987;21:274278

41 Niks EH, Kuks JB, Roep BO, Haasnoot GW Verduijn W, Ballieux BE, et al: Strong association of MuSK antibody-positive myasthenia gravis and HLA-DR14-DQ5. Neurology 2006;66:1772-1774.

42 Nikolic AV, Andric ZP, Simonovic RB, Rakocevic Stojanovic VM, Basta IZ, Bojic SD, et al: High frequency of DQB $1 * 5$ and absolute absence of DRB1*13 in muscle-specific tyrosine kinase positive myasthenia gravis. Eur J Neurol 2015;22:59-63.

43 Salvetti M, Ristori G, Bomprezzi R, Pozzilli P, Leslie RD: Twins: mirrors of the immune system. Immunol Today 2000;21: 342-347.

44 Shapira Y, Agmon-Levin N, Shoenfeld Y: Defining and analyzing geoepidemiology and human autoimmunity. J Autoimmun 2010; 34:J168-J177.

45 Lavrnić D, Jarebinski M, RakocevićStojanović V, Stević Z, Lavrnić S, Pavlović S, et al: Epidemiological and clinical characteristics of myasthenia gravis in Belgrade, Yugoslavia (1983-1992). Acta Neurol Scand 1999; 100:168-174

46 Simpson S Jr, Blizzard L, Otahal P, Van der Mei I, Taylor B: Latitude is significantly associated with the prevalence of multiple sclerosis: a meta-analysis. J Neurol Neurosurg Psychiatry 2011;82:1132-1141.

47 Pedersen EG, Hallas J, Hansen K, Jensen PE, Gaist D: Identifying patients with myasthenia for epidemiological research by linkage of automated registers. Neuroepidemiology 2011; $37: 120-128$. 